Revista Brasileira de Informática na Educação - RBIE Brazilian Journal of Computers in Education (ISSN online: 2317-6121; print: 1414-5685) http://br-ie.org/pub/index.php/rbie

Submission: 14/07/2020; Camera ready: 19/12/2020; $1^{\text {st }}$ round notif.: $27 / 10 / 2020$; Edition review: 23/12/2020;
New version: 18/11/2020; Available online: 22/01/2021; $2^{\text {nd }}$ round notif.: $15 / 12 / 2020$; Published: 22/01/2021;

\title{
Panda: Uma Nova Ferramenta Web Responsiva Para Auxiliar no Ensino e Comunicação de Pessoas com Limitações Psicomotoras
}

\author{
Panda: A new Web Responsive Tool to Assist in Teach and Communication of Psychomotor \\ Limitations People \\ Paulo Henrique Vieira Cândido \\ IFSP Campus Itapetininga \\ phvcandido@gmail.com \\ Vinicius A. O. Zevarex \\ IFSP Campus Itapetininga \\ vinicius.zevarex2002@gmail.com \\ João V. F. Morais \\ IFSP Campus Itapetininga \\ ifsp.joaov@gmail.com \\ Lucas F. A. Cavalherie \\ IFSP Campus Itapetininga \\ lucascavalherie01@gmail.com \\ Sylvia M. Santos \\ IFSP Campus Itapetininga \\ syll.martins@gmail.com \\ Pedro H. M. de Gois \\ IFSP Campus Itapetininga \\ pedromorais.gois@gmail.com
}

Carlos H. Silva-Santos

IFSP Campus Itapetininga

carlos.santos@ifsp.edu.br

\section{Resumo}

O desenvolvimento de tecnologias assistivas é uma tarefa complexa, devido a necessidade atender necessidades específicas de pessoas como as psicomotoras que limitam a comunicação delas ou serem de fato indivíduos não verbais. Nesse contexto, este trabalho apresenta um novo Software as a Service (SaaS) para criar livros para apoiar um sistema baseado em Picture Exchange Communication (PEC) para pessoas com Transtorno do Espectro Autista (TEA) com limitações de psicomotricidade e limitação parcial ou total na comunicação verbal. Esse SaaS foi chamado de Panda e desenvolvido utilizando tecnologias Progressive Web App (PWA) para oferecer facilidade ao usuário e flexibilidade de uso em diferentes tipos de dispositivos móveis, oferecendo recursos de interface baseados User Interface Design Patterns (UIDP). Alguns resultados com o grupo de usuários mostraram adequação à ferramenta e seu pleno funcionamento sem conexão com a Internet, mas que implicações negativas com alguns recursos de interface são descritas e que estão sendo incrementados pela equipe de desenvolvimento para o pleno atendimento das necessidades sociais e vasta abrangência de uso esperada.

Palavras-chave: Tecnologias Assistivas, Software como Serviço (SaaS), Sistema de Comunicação por Troca de Figuras (PECS) ®, Aplicações Web Progressivas (PWA).

\footnotetext{
Abstract

The development of assistive technologies is a complex task, by the demanding to attempt specific people with special such as psychomotricity limitations which could contributes to limit their communication or actually being nonverbal individuals. In this context, this work presents a novel Software as a Service (SaaS) to create books to support a system based on Picture Exchange Communication (PEC) for people with Autistic Spectrum Disorder (ASD) with psychomotricity limitations and partial or total limitation in verbal communication. This SaaS was called Panda and developed using Progressive Web App (PWA) technologies for a satisfactory human-interface usability and being enough flexible to be used in different types of mobile devices, offering User Interface Design Patterns (UIDP) based features. Results with a group of users showed suitability for the tool and its full functioning without an Internet connection, but that negative implications with some interface features are described and that are being increased by the development team to attempt social needs and wide range of expected use.

Cite as: Cândido, P. H. V., Morais, J. V. F., Santos, S. M., Zevarex, V. A. O., Cavalherie, L. F. A., Gois, P. H. M. \& Silva-Santos, C. H. (2021). Panda: A new Web Responsive Tool to Assist in Teach and Communication of Psychomotor Limitations People (Panda: Uma Nova Ferramenta Web Responsiva Para Auxiliar no Ensino e Comunicação de Pessoas com Limitações Psicomotoras). Brazilian Journal of Computers in Education (Revista Brasileira de Informática na Educação - RBIE), 29, 25-47. DOI: 10.5753/RBIE.2021.29.0.25
} 
Keywords: Assistive Technologies, Software as a Service (SaaS), Picture Exchange Communication System $(P E C S) \circledR$, Progressive Web Application (PWA)

\section{Introdução}

Os avanços tecnológicos têm interferido nas relações sociais e nas redes de comunicação dos seres humanos. Isso não se limita apenas às relações entre humanos, mas também com o meio e os objetos com o qual convivemos (Harari, 2016), (da Silva, do Nascimento, 2019). Como exemplo, tem-se a Internet das Coisas (IoT - Internet of Things) que estrutura conceitos de entidades inteligentes, como as cidades, casas, educação e indústria, em que a esse último emprega-se a nomenclatura 4.0 para linhas de produção automatizadas e controladas por sensores e robôs (Benesová \& Tupa, 2017).

Ainda neste contexto, também há de se considerar as contribuições que essas tecnologias podem proporcionar às práticas educativas e socialização de pessoas com necessidades especiais, como as diagnosticadas no espectro autista ou com limitações psicomotoras. Para essas pessoas novas tecnologias também têm sido propostas com o intuito de alterar seu cotidiano social e proporcionar mecanismos alternativos de comunicação, com motivador à facilitação da interação e inclusão social (Alabbas \& Miller, 2019).

Para isso, há contribuições quanto ao desenvolvimento de sensores que auxiliam no monitoramento da situação do ambiente e sinais vitais dessas pessoas, gerando notificações sobre estados fisiológicos ou até comportamentais, que sejam alertas de risco à saúde delas (Schuller et al., 2014), (Chatterjee, Aceves, Dungca, Flores, \& Giddens, 2016). Com esses exemplos, pode-se considerar as tecnologias como ferramentas facilitadoras à mobilidade e inclusão social de pessoas com limitações psicomotoras, assim como importantes recursos de monitoramento e meios de comunicação de suas necessidades.

Nesta perspectiva, este projeto apresenta um novo Software as a Service (SaaS) chamado Panda, que é extraído do sorteamento dos caracteres da afirmação Projecting a Different Assistive Technology, disponível em https://panda.itp.ifsp.edu.br, que tem por objetivo prover gratuitamente um ambiente simples para a criação de livros de imagens com descrições, baseandose no método PECS Picture Exchange Communication System para facilitar a comunicação de pessoas com limitações psicomotoras, incluindo os autistas, como representado na Figura 1 (AlBatayneh, Nazer, Khader, \& Owais, 2019).

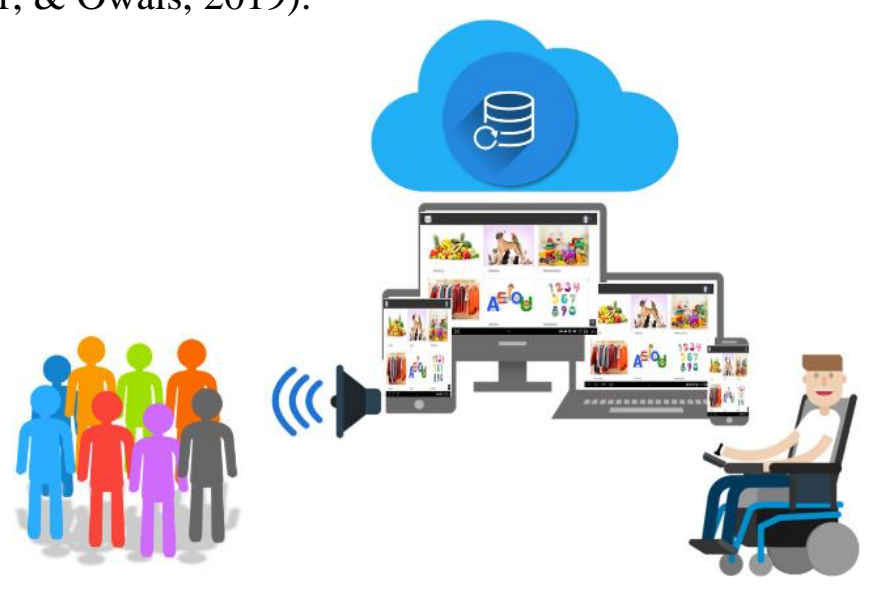

Figura 1: Esquemático de comunicação utilizando o Panda

As contribuições e inovações do Panda estão relacionadas às criações autônomas e que preservam as experiências de vida de cada indivíduo para a composição de diferentes livros PECS em um sistema simples na Internet e que facilmente pode ser utilizado em dispositivos móveis, 
acrescendo-se valores de acessibilidade, variedade no uso comunicativo e didático pelos familiares e professores de pessoas com limitações psicomotoras de forma gratuita.

Também há contribuição de um requisito de flexibilidade quanto ao uso em smartphones ou tablets com recursos computacionais limitados, tanto em hardware quanto em sistema operacional Android, disponíveis desde os anos de 2013. Para atender aos requisitos especificados neste projeto, esse SaaS vem sendo desenvolvido com tecnologias de Progressive Web Application (PWA) para funcionamento sem Internet, tendo por objetivo disponibilizar serviços de criação de livros comunicativos off-line.

A validação da interface da ferramenta foi realizada em experimentos controlados, com pessoas que apresentavam limitações psicomotoras em que se tinha por objetivo verificar a variedade de recursos interativos utilizando um tablet para a comunicação pela ferramenta sem conexão com Internet e a motivação deles em utilizar a ferramenta em sua comunicação. Esses experimentos motivaram a continuidade do trabalho com a inserção de novos recursos à uma versão com reconhecimento facial para a comunicação utilizando movimentos dos eixos ortogonais (cima, baixo, direita e esquerda) da cabeça das pessoas.

Para apresentar o desenvolvimento e os resultados obtidos neste trabalho inicia-se na segunda seção definições conceituais sobre psicomotricidade e tecnologias assistivas. Na terceira seção variações de recursos para o desenvolvimento de SaaS com atenção a variedade interativa da interface. Essas duas seções confluem à quarta em que se apresenta a fundamentação metodológica deste projeto, para a consequente apresentação dos resultados de desenvolvimento na quinta seção e experimentos controlados com os usuários na sexta seção, onde descreve-se a avaliação com pessoas atendidas em uma entidade assistencial para pessoas com necessidades especiais. Por fim, as considerações e trabalhos em andamento são apresentados na sexta seção.

\section{Tecnologias Assistivas para Pessoas com Limitações Psicomotoras}

A habilidade fundamental de movimento (Fundamental Movements Skill - FMS) é termo usual para se associar parâmetros a serem relacionados nas diferentes áreas de atuação do indivíduo como, por exemplo, atividades físicas ou entretenimento (Maïano, Hue, \& April, 2019), (Logan,Ross, Chee, Stodden, \& Robinson, 2018). Partindo desse conceito, surgem terminologias associadas aos processos avaliativos, representação e conhecimento nas diferentes áreas de exploração do corpo humano e suas interações como na psicologia, fisiologia e outras (Logan et al., 2018).

Para a delimitação do escopo deste trabalho, considerou-se a definição de psicomotricidade como sendo o desenvolvimento holístico da "atividade física" por meio de experiências voluntárias, distante de avaliações da capacidade e mérito (Suh \& Kim, 2016). Portanto, ao se considerar as experiências das pessoas que possuem limitações psicomotoras utilizando tecnologias sob a perspectiva de psicomotricidade aqui definida, as práticas devem ser realizadas com bastante cuidado, atentando-se para que elas não se sintam avaliadas e busquem por resultados meritosos.

O desenvolvimento de tecnologias voltadas ao auxílio da comunicação dessas pessoas com limitações psicomotoras deve considerar a maior variedade clínica possível, dentre as quais se enquadram no Transtorno do Espectro Autista (TEA). Neste caso, ponderações acerca de cuidados quanto à hipersensibilidade ao toque, luminosidade e ao som são importantes fatores que podem influenciar no uso dos recursos computacionais para sua comunicação, dentre as quais as aplicadas ao método PECS (Tornblad, Jones, \& Inan, 2019).

O PECS é um método de comunicação que vem sendo aplicado e estudado na literatura em diferentes contextos, países e tecnologias, inclusive com recentes registros de propriedade intelectual em patentes (Bruno, Schuchman, Cunningham, \& McCarthy, 2001), (Raja, Saringat, Mustapha, \& Zainal, 2017), (Raja et al., 2017). 
Por outro lado, no Brasil há uma carência de pesquisa aplicada e estudos sistêmicos de pessoas com limitações psicomotoras e TEA. Nesta afirmação também deve-se incluir as formações de profissionais nessa área de atuação, pois nacionalmente tem se focado na teoria e a prática ocorrendo apenas em suas atividades profissionais do cotidiano (Dias, 2016).

Para se justificar essa complexa afirmação da situação na área assistiva no Brasil, relatase que não existem dados epidemiológicos representativos no país em relação a pessoas com TEA, mas apenas dados amostrais com taxas que variam de $0,25 \%$ à $1 \%$ da população que se enquadre com TEA, sendo este último número mais próximo da realidade internacional (Portolese, Bordini, Lowenthal, Zachi, \& Paula, 2017).

Essa problemática se agrava ao se considerar que o país possui extensão territorial continental e com uma população aproximada de 209,3 milhões de pessoas e que em estudos realizados por J. Portoles et. al (2017) há apenas 650 unidades de atendimento especializado às pessoas com TEA. Sendo que destas, 431 (66,31\%) encontram-se no Estado de São Paulo e nenhuma no Estado de Roraima, o qual tem próximo de 500 mil habitantes.

Nessa perspectiva, tecnologias que sejam disponíveis mais facilmente no mercado, disponibilizadas gratuitamente pela Internet e que possam ser adaptadas com pouco conhecimento tecnológico são importantes para facilitar o dia a dia das pessoas e ter a maior abrangência possível no país.

\subsection{Estudos de Casos com Tecnologias Assistivas para Auxiliar na Comunicação e Educação de Pessoas com Limitações Psicomotoras}

No Brasil, há diferentes iniciativas para o desenvolvimento de tecnologias assistivas voltadas à facilitação da comunicação, nas quais são usualmente designadas como Sistemas de Comunicação Aumentativa ou Alternativa (SCAA) (Da Silva Júnior, \& Da Hora Rodrigues, 2019), dentre as quais destaca-se a já mencionada PECS que é foco de aplicação neste trabalho (Tornblad, Jones, \& Inan, 2019).

Nessa perspectiva, tem-se como exemplo a ferramenta aBoard da UFPE apresentada por Franco et al. (2017). Essa é uma ferramenta que já funciona em nuvem e os autores disponibilizam na Play Store um aplicativo para funcionar off-line. Nesse trabalho, inclusive, eles apresentam uma comparação com outros aplicativos da loja que foram selecionados segundo critérios de números de download e boa avaliação, para comparar diferentes requisitos agrupados em três características básicas de conteúdo, expressão e navegação. Além disso, na sequência os autores comparam novamente o aBoard com Adapt e LetMeTalk tomando-se como base as 10 Heurísticas de Nielsen, para se ter uma análise de interface e recursos do aplicativo desenvolvido por eles. Semelhante ao presente trabalho, no qual, além dos testes com usuários na APAE de Itapetininga, também são indicados uma análise com os mesmos parâmetros para as características básicas e Heurísticas de Nielsen na seção 5.1 referente aos resultados de desenvolvimento do sistema.

Neste mesmo segmento, há também a ferramenta ABC Autismo desenvolvido por Farias, Silva \& Cunha (2014) com o objetivo de auxiliar o aprendizado de pessoas com autismo. Ele foi desenvolvido na linguagem de programação Java, estando disponível apenas para sistema operacional Android. Além disso, sua concepção foi voltada para suportar o modelo baseado em problemas criado para o Tratamento e Educação para Autistas e Crianças com Déficits Relacionados à Comunicação, que é reconhecido pelo acrônimo TEACCH® originário do termo em inglês Treatment and Education of Autistic and related Communication-handicapped Children. Nesse trabalho os autores demonstram resultados promissores com usuários e que são comentados com uma perspectiva pedagógica por Mentone e Fortunato (2019) que, ao comparálo com outras duas ferramentas chamadas Aiello e SCAI Autism, concluem que o ABC Autismo se sobressai com sucesso em todos os requisitos analisados, enquanto as outras duas ferramentas apresentam certas limitações. 
Fora do âmbito nacional, tem-se também a parceria binacional entre Portugal e Estados Unidos consolidada pela ferramenta chamada Crescendo, desenvolvida por Cesário, Rodrigues, Wu \& Nisi (2016). Os autores propõem o desenvolvimento de uma ferramenta baseada no método vSked para aprendizado e apresentado por Cramer et al. (2011) em associação com a comunicação baseada no método PECS. Essa relação das técnicas foi necessária para a proposta de um ambiente em que a criança ou pessoa autista imerge num mundo virtual com navegação guiada pelos professores, os quais auxiliam na construção do significado dos objetos do mundo real e a execução de atividades de maneira mais autônoma, visando uma inclusão social mais ampla.

Por fim, o trabalho de Paim (2019) apresenta comparativos de ferramentas educacionais para pessoas enquadradas no TEA, indicando como baixar e utilizar alguns de seus recursos. Nesse trabalho, a autora analisa as ferramentas ABC Autismo, Lima Educa, OTO (Olhar, Tocar, Ouvir), Bariny Mouse e Autastico, inclusive com definições sobre as diferentes técnicas de exploração das ferramentas como PECS, TEACCH e ABA (Applied Behavior Analysis).

\section{Conceitos Tecnológicos para o SaaS}

O inter-relacionamento tecnológico na computação vem se ampliando e maximizando a complexidade no desenvolvimento das soluções. Isso, por consequência, também tem requerido mão-de-obra qualificada, diferentes tecnologias, procedimentos de testes das ferramentas e o emprego de testes na validação com potenciais usuários (Briand, Nejati, Sabetzadeh, \& Bianculli, 2016).

Para exemplificar, quando se intenta pelo desenvolvimento de um SaaS há de se considerar diferentes testes matemáticos de robustez quanto as trocas customizadas e emparelhamento de dados (Tsai \& Qi,2017), (da Silva, Correa, Dias, \& da Cunha, 2015), segurança física e de software (Siddiqui \&Ahmad, 2016) e usabilidade (Grigera, Garrido, Rivero, \& Rossi, 2017).

Essa afirmação baseia-se na disponibilidade de serviços online que possam ser considerados críticos e que se interligam com diferentes finalidades, despertando interesse de inovação e registro de propriedade intelectual de gigantes da tecnologia como o Google e Amazon Pugh, Eakes, Bernander \& Gundavaram, 2015), (Johnston \& Palaniappan, 2015).

Esses requisitos têm usualmente se associado a necessidades disruptivas e a consequente etapa democratização da tecnologia para que ela chegue ao público, tendo como pressuposto de que o custo deva ser baixo. Isso é comumente mais bem visualizado no SaaS quando associado a recursos de IoT, quando há necessidade de provimento de garantias de funcionamento tanto de hardware quanto software (Mania, da Silva Santos, \& Alvaro, 2014).

Para elucidar a importância de integração dessas tecnologias de maneira simples, hoje tem se tornado mais comum a aquisição de recursos de IoT voltados às necessidades das pessoas com dispositivos vestíveis (Aliverti, 2017), sensores residenciais (Hamdan, Shanableh, Zaki, Al-Ali, \& Shanableh, 2019) e no controle de animais de estimação (Wang, 2020). Os dados gerados nesses dispositivos são enviados pelas aplicações, quando conectados à Internet, a ao menos um SaaS para o seu gerenciamento, emissão de notificações e até proporcionar-lhes experiências diferenciadas, como as construídas por aprendizado de máquina (Pop, 2016).

A escalabilidade na quantidade e variedade de usuário de um SaaS, em especial ao aqui proposto, deve ser devidamente planejado e validado, levando principalmente em consideração pesquisas de Interação Humano-Computador (IHC), como na necessidade de adaptação e multimodalidade de interfaces. Esta última que está relacionada às diferentes formas de IHC, quanto ao toque na tela, teclado, mouse, movimentos gestuais ou faciais e outros (Bueno, 2017).

Devido a todas essas informações pessoais que podem ser exploradas trafegadas pela Internet, também se faz necessário o estabelecimento de requisitos ao mantimento da privacidade e personalização dos recursos dos indivíduos (Munteanu et al.,2015) (Esposito, Esposito, \& Vogel, 2015). 
Nesse cenário tecnológico dinâmico e interativo baseado em nuvem computacional (Bhushan, Reddy, Subramanian, \& Gao, 2018), o desenvolvimento de serviços disponibilizados na Internet têm passado por constantes transformações tecnológicas como na disponibilização de recursos baseados em microsserviços (Rangasamy, Kumar, Jeyapaul, \& Lillie, 2016) e aplicações Web progressivas, usualmente conhecidas como PWA (Progressive Web Application), que vêm sendo consideradas tendências de mercado (Girdhar, Srivastava, \& Rawat, 2019), (SEKSENOV, Chinnathambi, HILL \& BURTOFT, 2019).

Os microsserviços são conceitualmente desenvolvidos para disponibilizar recursos específicos auxiliando os desenvolvedores na implementação de aplicações com variabilidade nos mecanismos interativos de interface e sua associação aos controladores de recursos, sendo também planejados para serem integrados a diferentes frameworks para auxiliarem no desenvolvimento dos sistemas Web (Bueno, 2017), (Mendonça, Jamshidi, Garlan, \& Pahl, 2019), (Freitas, 2018).

Um exemplo de uso desses recursos, neste projeto está em etapas de testes com recursos desenvolvidos para comunicação das pessoas com limitações psicomotoras por meio do reconhecimento de movimentos faciais, sendo aqui integrados por um microsserviço com a biblioteca OpenCV, a qual disponibiliza recursos de processamento de imagens e detecção de pontos característicos das faces ou outras partes pré-definidas do corpo humano (Mortazavi, Salehe, Gomes, Phillips \& de Lara, 2017), (Amos, Ludwiczuk, Satyanarayanan et al., 2016). Esse tipo de recurso pode também poderá ser futuramente reutilizado por recursos planejados para o controle de acesso biométrico (Upadhyay, Rida, Gupta \& Siddique, 2017) e o reconhecimento de idade, sexo ou outras propriedades fenotípicas de seres humanos (Salihbasí c \& Orehovacki, 2019), que podem estar associados à recursos de segurança da ferramenta (Sayem \& Chowdhury, 2018).

Portanto, percebe-se que para as tecnologias assistivas são necessários diferentes recursos e conceitos de interatividade e visualização de dados, assim como localização espacial, relacionamento em ecossistema digital e ferramentas que auxiliem pessoas com limitações psicomotoras na inclusão social (Mukhopadhyay, 2019), (Ramaci, 2019), (Tang, Hu, Xu, \& Zhu, 2019).

\section{Metodologia e Tecnologias Empregadas no Desenvolvimento do Panda}

Neste trabalho, como já descrito, parte-se do pressuposto do baixo custo para o reuso das tecnologias e a praticidade de reprodução com facilidade pela sociedade e, em especial, com aplicações gratuitas a serem disponibilizadas às pessoas com limitações psicomotoras. Também se toma a necessidade da fácil disponibilidade online, visando atender a extensão continental do país.

Portanto, seu processo de planejamento, desenvolvimento e análise perpassa pela avaliação de interface de um aplicativo para pessoas com limitações psicomotoras, visando analisar sua interação com um dispositivo móvel para manusear o software nomeado de Panda, visando potencializar a interação humano-computador.

Para isso, considerou-se a necessidade de validação com pessoas com TEA para a experimentação, com o objetivo de aumentar o número de pessoas atendidas pela tecnologia. Por esse motivo, esse projeto foi submetido e aprovado pelo comitê de ética em pesquisa do Instituto Federal de Educação, Ciência e Tecnologia de São Paulo - IFSP Campus Itapetininga. Os experimentos foram realizados na Associação de Pais e Amigos de Excepcionais (APAE) da cidade Itapetininga em duas diferentes salas pré-selecionadas por uma professora com experiência no atendimento de pessoas com necessidades especiais, totalizando 11 pessoas sendo analisadas em duas diferentes salas. Os resultados dos experimentos são apresentados na Seção 6. 
Da perspectiva do desenvolvimento tecnológico do Panda, tanto de Front-end quanto de Back-end do sistema, ponderaram-se os requisitos de usabilidade, acessibilidade, portabilidade para diferentes dispositivos móveis com recursos limitados de Hardware e Sistema Operacional e com tempo de resposta ao toque à oralização via sintetizador de voz do dispositivo. A esse último requisito levou-se em consideração que há dispositivos móveis que limitam a instalação de diferentes navegadores de internet utilizados atualmente.

Visando facilitar a apresentação metodológica e de desenvolvimento deste trabalho, seu detalhamento foi dividido nas subseções 4.1 para o Back-end e 4.2 para o Front-end.

\subsection{Desenvolvimento Back-end}

Como requisito já mencionado, o atendimento à dispositivos móveis tidos como ultrapassados e que possuem sistemas operacionais que limitam a instalação de diferentes navegadores, tem-se como ponto de partida para o desenvolvimento que os usuários não tivessem de instalar aplicativos e a sincronização de dados desses dispositivos com a nuvem computacional quando conectados com a Internet, por isso optou-se pelo uso das tecnologias PWA (Progressive Web Application).

Devido ao ponto de partida estabelecido e os recursos, microsserviços e frameworks disponíveis, passa a ser necessário utilizar a arquitetura MVC (Model, View and Controller) (Ma, Yang, Wang, Liu, \& Zhang, 2019) e esquematizado na Figura 2, com as respectivas tecnologias utilizadas neste projeto.

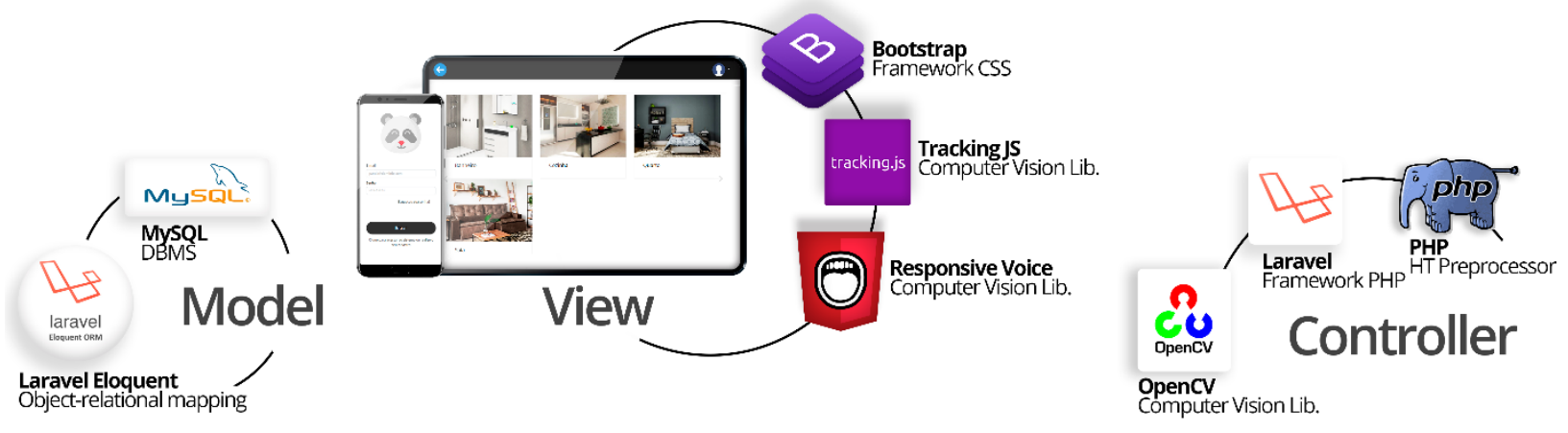

Figura 2: Esquemático M.V.C. com os recursos utilizados em cada camada.

No back-end do sistema há de se considerar as camadas Model e Controller. Na camada Model dois importantes recursos incluídos, sendo o framework Laravel ${ }^{1}$ e o Sistema Gerenciador de Banco de Dados (SGBD) MySQL ${ }^{2}$. O Laravel provê uma estrutura básica para desenvolver sistemas Web, disponibilizando recursos para se trabalhar com diferentes formas de estrutura de armazenamento de dados, tanto relacionais quanto não relacionais.

Por se considerar essa flexibilidade quanto à estruturação dos dados e a possibilidade de escalar esse sistema com outras aplicações assistivas que venham a ser de interesse e com recursos de IoT, optou-se por um modelo organizacional das imagens e livros utilizando grafos estruturados em árvores (Figura 3). Essa estrutura pode possibilitar a troca de ramos de livros entre usuários de maneira mais organizada e que pode, se necessário, facilitar a troca de dados com bancos não-relacionais futuramente.

\footnotetext{
${ }^{1} \mathrm{https} / / /$ laravel.com/

2 https://www.mysql.com/
} 


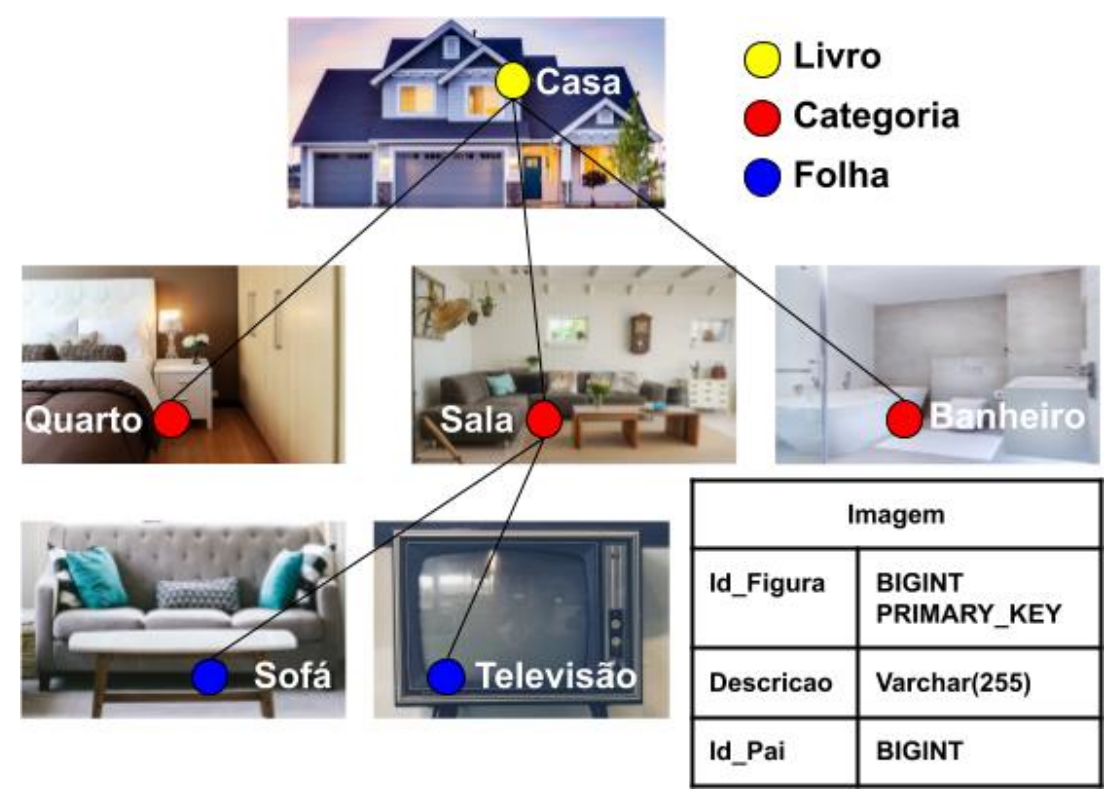

Figura 3: Modelo da Estrutura da Dados e sua representação de relacionamento por grafo.

Com essa estrutura de dados e os recursos tecnológicos de desenvolvimento, podem-se controlar os relacionamentos dos usuários com seus diferentes livros apenas buscando-se por um ponteiro ao nó raiz da árvore que representa cada livro. Isso agiliza a busca na base dados modelados em uma única estrutura (tabela) para o armazenamento no SGBD. A Figura 3 apresenta um esquemático em que há o estabelecimento de atributos associados aos códigos de identificação das imagens, suas respectivas descrições a serem utilizadas pelo sintetizador de voz e um outro campo para armazenar o índice do nó referente ao pai deste, quando este houver.

$\mathrm{Na}$ sequência, a camada Controller é quem organiza os livros hierarquicamente em categorias e as folhas das árvores representando a imagem de interesse para a comunicação. Nessa estrutura hierárquica e em árvore, quando a imagem armazenada no banco de dados não possui um nó pai, ela passa a ser a capa do livro, ou seja, raiz dessa árvore, conforme representado em amarelo na Figura 3. Quando o registro é identificado como pai de algum outro nó, ele é tido como uma categoria no livro (representado em vermelho) e as folhas (azul) são designadas quando elas não têm filhos e possuem um pai associado.

Para facilitar a compreensão dessa estrutura de árvore na Figura 3, foi exemplificado com um livro que abstrai uma casa (amarelo) em que as categorias (vermelho) estão associadas a alguns de seus cômodos e as folhas são objetos disponibilizados em cada uma das categorias. Portanto, se houver um sofá no quarto e outro na sala, eles serão diferentes na estrutura organizacional. Ainda, por isso há no sistema a configuração para que o sintetizador de voz processe os textos das imagens tanto das categorias quanto das folhas dos livros.

Outra responsabilidade do Controller está relacionada a interconexão entre os recursos das diferentes camadas MVC, sendo operacionalizada com o Framework Laravel. O Laravel é um framework em PHP que oferece o Eloquent ORM, que é um sistema de armazenamento ativo (ActiveRecord) que permite a integração e comunicação direta entre as camadas Controller e Model (Stauffer, 2019). Ele também possui integração nativa com SGBD com o Eloquent, como PostgreeSQL, SQLite, SQL Server e o MySQL.

Para o requisito de funcionamento sem Internet (off-line) com o conceito de Progressive Web Apps (PWA) é necessária a implementação de tecnologias que manipulem o cache do aplicativo e navegador (Biørn-Hansen, Majchrzak, \& Grønli, 2017). Sendo que estes são oferecidos pelo HTML5, como o App Cache, o qual permite o armazenamento em cache de arquivos especificados pelo desenvolvedor assim que a conexão é considerada segura. 
Para a implementação de tal funcionalidade foi necessário criar um vínculo do manifest, que faz o controle dos arquivos como rota do Laravel e que utiliza o mapeamento de objetorelacional (ORM) para criação de páginas. Isso possibilita a modificação dinâmica dos arquivos em cache, sincronizando a memória temporária de cache com o banco de dados instanciado por cada usuário em seus dispositivos (Basques, 2020).

Além disso, é importante mencionar o uso de Service Workers, por ser outro recurso manipulado por Javascript e que trabalha internamente ao aplicativo para verificar a possibilidade da instalação. Quando a conexão é classificada como segura ele é instalado e ao ser concluído o Service Workers é ativado passando a ser possível utilizar sua função de busca (Gaunt, 2019).

Ambos os recursos anteriores, o App Cache e o Service Workers, possuem o mesmo fim, disponibilizar a página Web para o usuário sem acesso à Internet. Porém, apesar da simplicidade de instalação de App Cache e da menor quantidade de processos para sua instalação automática nos dispositivos móveis, ele está entrando em desuso e não será mais disponibilizado por navegadores. Em vista disso, para suprir futuras implementações, ambos os recursos foram adicionados ao Panda (Network, 2019).

\subsection{Desenvolvimento Front-end}

O desenvolvimento da interface do sistema está na camada View e usualmente é chamado de frontend em aplicações móveis e Web (Ma et al., 2019). Nesta aplicação assistiva a interface tem como requisitos essenciais o suporte à sensibilidade ao contexto e às multimodalidades de interação, partindo-se dos movimentos de toque e teclas personalizadas com recursos associados ao clássico teclado do tipo swipe. Também são incorporados recursos preliminares de reconhecimento de movimentos da cabeça (cima, baixo, esquerda e direita) para a interação com câmera de baixa resolução de dispositivos móveis.

A sensibilidade ao contexto é a capacidade que a interface tem de se adaptar ao dispositivo em que está sendo executada e ao contexto em que está sendo utilizada. A adaptação às telas de diferentes tamanhos de diferentes dispositivos é um exemplo do suporte à sensibilidade ao contexto (Harb, Kapellari, Luong, \& Spot, 2011), (Bueno, 2017).

Para isso, a utilização de técnicas de Responsive Web Design (RWD) se mostraram interessantes opções para a utilização de um Framework Front-end $(\mathrm{FeF})^{3}$ (Maldonado, Braga, Germano, \& Masiero, 2002), (Harb et al., 2011). A escolha do FeF para a interface baseou-se nas pesquisas realizadas por (Bueno, 2017), (Jain, 2015) e (Cândido, 2017), que o Bootstrap ${ }^{4}$ mostrou-se mais consistente e com menor quantidade de falhas de interação e facilidade de implementação comparado a outros FeF.

Outro conceito mencionado é a multimodalidade de interação, que tem como base as formas com que o usuário interagirá com a interface através do dispositivo, que neste caso serão por (a) toque e (b) pela câmera do dispositivo com os movimentos da cabeça.

A interação por toque foi considerada a principal modalidade de interação com a interface. Com isso, para suprir possíveis problemas de interação, a utilização de UIDP (User Interface Design Patterns) mostrou-se necessária, visto que UIDP são resultados de pesquisas para resolução de problemas de interação recorrentemente encontrados no desenvolvimento de interfaces e são classificados e agrupados em bibliotecas UIDP, como o UI Patterns, em que os padrões implementados no Panda foram analisados (Doosti, Dong, Deka, \& Nichols, 2018), (User Interface Design Patterns, 2016).

Para a interação por meio da câmera dos dispositivos móveis, utilizando o movimento da cabeça como modalidade, considerou-se os requisitos não funcionais de privacidade e usabilidade

\footnotetext{
${ }^{3}$ Conjunto estruturado de recursos de User Interface Design Patterns (UIDP) baseados e construídos a partir de experiências adquiridas por outros desenvolvedores para resolução de problemas já encontrados - e em geral desenvolvidos com técnicas de RWD

${ }^{4}$ https://getbootstrap.com.br/
} 
básicos à sua execução. Para isso, a cada primeiro acesso à área de utilização de reconhecimento facial do Panda o navegador solicita a permissão de acesso à câmera do dispositivo.

Com o acesso permitido à câmera, o Panda pode analisar as informações recebidas, com isso, torna-se possível a captação dos movimentos juntamente com o reconhecimento da face do usuário. Para tanto, utilizou-se dos recursos disponibilizados pela biblioteca Javascript Tracking, que utiliza do método LBF (Local Best-fit), além de sintetizar funções do OpenCV para tal análise em front-end. Sua documentação está disponível em seu site oficial https://trackingjs.com (Landgren, 2019).

\section{Resultados no Desenvolvimento do Software}

Com os recursos requeridos ao desenvolvimento do Panda, seu projeto visual foi planejado como uma grade utilizando os pontos focais, com uma página Web com 6 figuras em cada, para que ficassem esteticamente organizadas nos diferentes dispositivos e acessíveis às pessoas com limitações psicomotoras e TEA, conforme resultados de implementação apresentados na Seção 5.1 comparando com a ferramenta aBoard e os resultados experimentais apresentados na sexta seção. Abaixo das imagens aparece em letras com menor destaque as palavras que serão processadas pelo sintetizador de voz do dispositivo.

Porém, para se manter a privacidade dos usuários, antes deles acessarem o sistema há um processo de acesso com login e senha, como ocorre em parte dos aplicativos em que após o primeiro acesso no dispositivo isso não é mais solicitado novamente. Todos esses recursos foram planejados seguindo o design minimalista com a menor quantidade de imagens que maximizam as informações na tela (Soderstrom, Carlsson, \& Mejtoft, 2019). Ademais, apenas recursos de informação sobre o caminho percorrido pelos usuários no sistema foram fornecidos na barra superior da Interface para que o usuário com maior familiaridade com aplicativo pudesse se deslocar com maior agilidade no livro em uso, conforme apresentado na Figura 4.

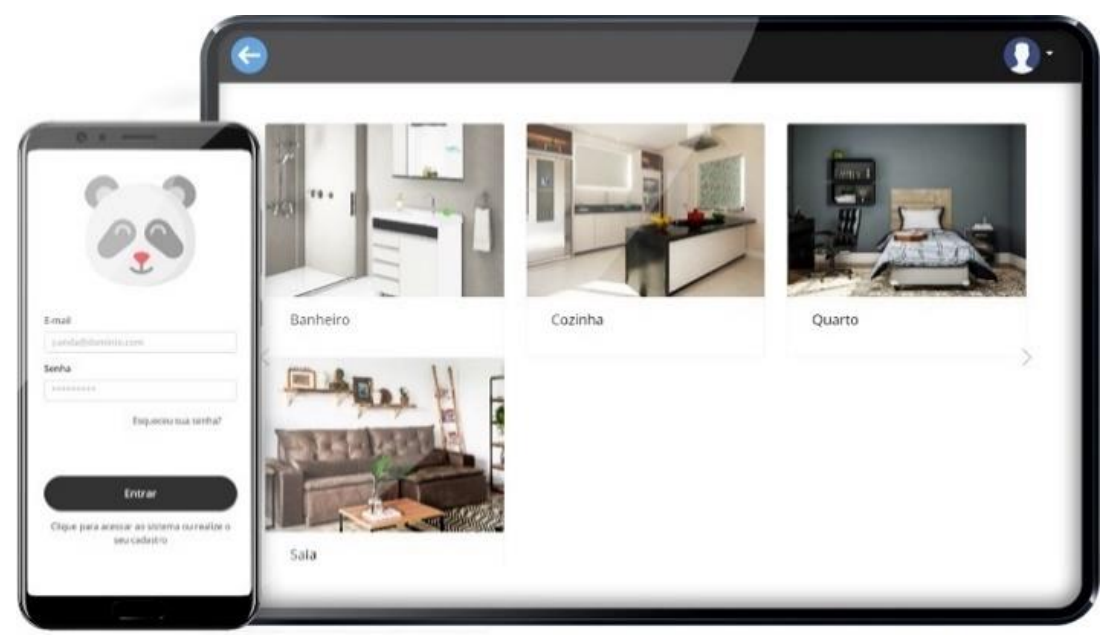

Figura 4: Áreas de login e livros do sistema

O desenvolvimento dos recursos indicados na Figura 4 foi simplificado pela adoção do Framework Bootstrap, por ter uma documentação bem estruturada ao se utilizar os recursos de Input Feedback, Input Prompt, Good Defaults e Wizard. Além disso, foram necessárias algumas meta tags do HTML5, para possibilitar a auto adaptação da interface às dimensões dos diferentes dispositivos testados.

O controle de exibição e transição das páginas associando a hierarquia em árvore dos livros requereu um algoritmo de busca em profundidade em árvores para realizar as buscas de maneira 
correta no banco de dados e retornar à sequência esperada pelos usuários. Associado a isso, como mencionado, o design minimalista foi pensado para o maior conforto visual dos usuários que terão essas telas como principais de uso, que provavelmente passarão mais tempo nelas. Por isso, seguindo os critérios planejados, foram implementados alguns UIDP reutilizando códigos disponíveis nas bibliotecas mencionadas, dentre os quais o Vertical Dropdown Menu, Cards, Carousel e Thumbnail para habilitar as transições e visualização das imagens na tela, como apresentado na Figura 5

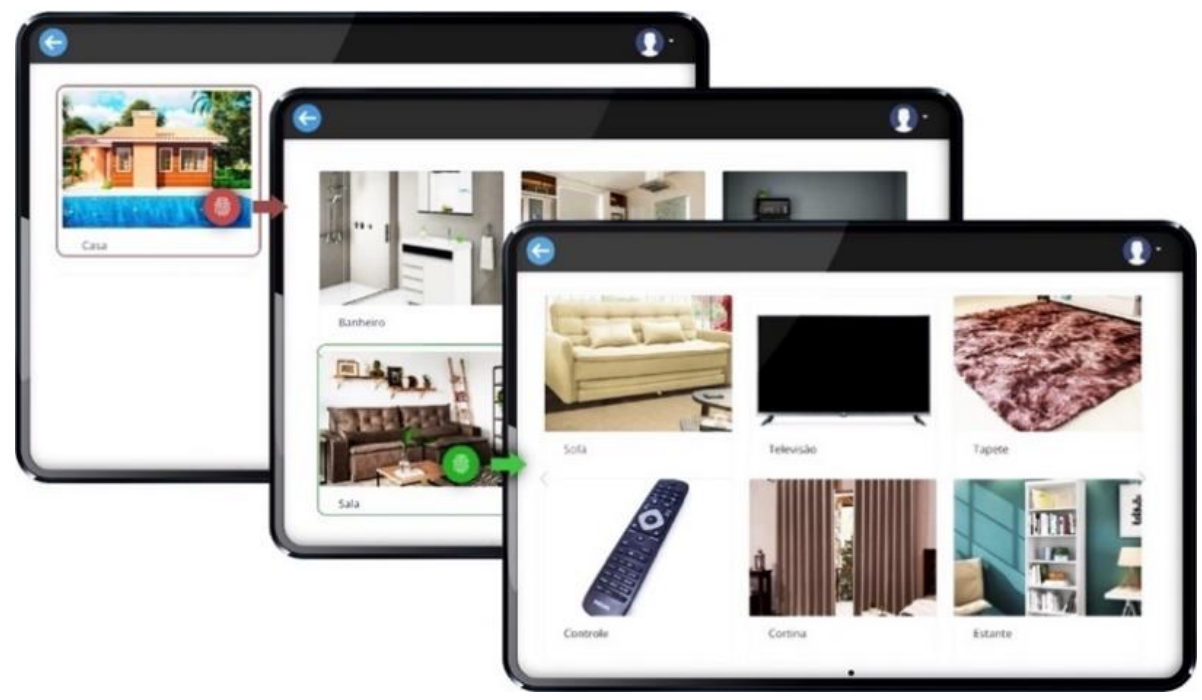

Figura 5: Interface de escolha de livros.

Além dos recursos visuais, tem-se o importante recurso de sintetização de voz do aplicativo que quando a pessoa seleciona uma imagem, ela sintetiza o texto associado a ela, sendo essa a forma de comunicação das pessoas com limitações psicomotoras.

Essa implementação foi complexa, ao se considerar como requisitos mínimos o tempo de resposta com dispositivos móveis já ultrapassados e volume de voz audível a até 2 metros de distância. Para isso, uma variabilidade de testes foi necessária para se validar e diferentes dispositivos móveis foram utilizados, inclusive um Tablet Positivo YPY 10 de 9,7 polegadas com Android 2.3 com $10 \mathrm{~GB}$ de armazenamento interno e RockChip dualcore de $1.5 \mathrm{GHz}$ (máximo) com $1 \mathrm{~Gb}$ de RAM, que foi um modelo de Tablet distribuído aos professores de ensino básico pelo FNDE nos anos de 2014/2015.

Isso foi necessário pois a sintetização de voz em dispositivos móveis, quando controlados por aplicativos nativos, é feita diretamente nele, por outro lado no Android esta pode ser também feita pela Application Programming Interface (API) Cloud Text-to-Speech.

Contudo, visando a utilização de um Web App disponibilizado pela internet e construído utilizando os conceitos e tecnologias de PWA, buscou-se por bibliotecas que disponibilizassem tal recurso diretamente nos navegadores. Neste sentido, utilizou-se a biblioteca Responsive Voice $^{5}$, que utiliza uma API online para sintetização da fala no aplicativo.

\subsection{Resultados no Desenvolvimento do Software}

Esta seção apresenta comparações entre a ferramenta desenvolvida neste trabalho (Panda) e o aBoard apresentada por Franco et al. (2017). Para esse fim, reproduz-se a seguir as duas tabelas baseadas no segundo trabalho, apresentando primeiro a comparação relacionada às Heurísticas de Nielsen de um modo geral (Tabela 1) e, em seguida, relacionadas às características de conteúdo, expressão e navegação (Tabela 2), desconsiderando as demais ferramentas.

\footnotetext{
${ }^{5}$ https://responsivevoice.org/
} 
Na Tabela 1, que é uma reprodução de resultados de Franco et al. (2017) para avaliar o aBoard, para comparação genérica pelas Heurísticas de Nielsen, observa-se um pequeno aumento percentual do Panda em relação ao aBoard, no qual atingiu 94\% e o aBoard $91 \%$. Essas comparações de médias descartaram as Heurísitcas 5 e 9 que não foram avaliadas por Franco et al. (2017) para o aBoard. Desse modo, percebe-se que apenas os critérios do manual e sistema de ajuda que precisam ser mais bem implementados no Panda para potencializar sua avaliação por essas Heurísticas.

Tabela 1: Comparação de desempenho do aBoard e Panda pelas Heurísticas de Nielsen conforme apresentado por Franco et al. (2017).

\begin{tabular}{|c|l|c|c|}
\hline Heurística & \multicolumn{1}{|c|}{ Funcionalidade } & aBoard & Panda \\
\hline 1 & Visibilidade do estado do sistema & $100 \%$ & $100 \%$ \\
\hline 2 & Correspondência entre o sistema e o mundo real & $83,3 \%$ & $100 \%$ \\
\hline 3 & Controle do usuário e liberdade & $42,86 \%$ & $75 \%$ \\
\hline 4 & Consistência e padrões & $100 \%$ & $100 \%$ \\
\hline 5 & Prevenção de erros & $\begin{array}{c}\text { Não } \\
\text { avaliada }\end{array}$ & $100 \%$ \\
\hline 6 & Reconhecimento ao invés de recordação & $100 \%$ & $100 \%$ \\
\hline 7 & Flexibilidade e eficiência de utilização & $100 \%$ & $100 \%$ \\
\hline 8 & Estética e design minimalista & $100 \%$ & $100 \%$ \\
\hline 9 & Reconhecimento, diagnóstico e recuperação de erros & $\begin{array}{c}\text { Não } \\
\text { avaliada }\end{array}$ & $75 \%$ \\
\hline 10 & Ajuda e documentação & $100 \%$ & $75 \%$ \\
\hline \multicolumn{2}{|l|}{ Média das Heurísticas Avaliadas nos dois softwares } & $\mathbf{9 1 \%}$ & $\mathbf{9 4 \%}$ \\
\hline
\end{tabular}

A segunda comparação reaproveitada do trabalho de Franco et al. (2017) considera a associação das Heurísticas de Nielsen com três diferentes características (conteúdo, expressão navegação) e são apresentadas na Tabela 2. Nesses requisitos, o Panda recebeu duas avaliações inferiores ao aBoard, por ter sido pensado para um pequeno conjunto de palavras e não expressões ou parágrafos completos. Com isso, na média geral, considerando as pontualidades dos requisitos, houve apenas uma diferença de 4,4\% a menos para Panda, que ficou com 73,9\% de sucesso nos itens avaliados contra os $78,3 \%$ do aBoard. 
Tabela 2: Heurísticas de Nielsen associadas à requisitos e agrupadas por características de conteúdo, expressão e navegação, baseando-se na disposição e resultados apresentados por Franco et al. (2017) para aqui comparar o aBoard com o Panda.

\begin{tabular}{|c|c|c|c|c|c|}
\hline$\#$ & Característica & Heurística & Funcionalidade & aBoard & Panda \\
\hline 1 & \multirow{10}{*}{ Conteúdo } & 1 & $\begin{array}{l}\text { Legendas na parte superior do } \\
\text { pictograma }\end{array}$ & Sim & Sim \\
\hline 2 & & 2 & Disponibilidade de cópia de conteúdo & Sim & Não \\
\hline 3 & & 3 & $\begin{array}{l}\text { Alteração da posição de qualquer } \\
\text { pictograma na área de conteúdo }\end{array}$ & Não & Não \\
\hline 4 & & 3 & Imagem customizada & Não & Sim \\
\hline 5 & & 3 & Áudio customizado & Não & Sim \\
\hline 6 & & 4 & Rolagem do conteúdo por paginação & Sim & Sim \\
\hline 7 & & 7 & $\begin{array}{l}\text { Comunicação paralela à construção da } \\
\text { expressão }\end{array}$ & Sim & Sim \\
\hline 8 & & 7 & Sugestão ou predição de pictograma & Sim & Não \\
\hline 9 & & 8 & Interface simples & Sim & Sim \\
\hline 10 & & 10 & Tutorial e ajuda disponíveis & Sim & Sim \\
\hline & & & $\begin{array}{l}\text { Sim } \\
\text { Não }\end{array}$ & $\begin{array}{l}\mathbf{7}(\mathbf{7 0} \%) \\
\mathbf{3}(30 \%) \\
\end{array}$ & $\begin{array}{l}7(\mathbf{7 0} \%) \\
\mathbf{3}(30 \%) \\
\end{array}$ \\
\hline 11 & \multirow{7}{*}{ Expressão } & 1 & $\begin{array}{l}\text { Expressões com pictogramas e suas } \\
\text { legendas }\end{array}$ & Sim & Sim \\
\hline 12 & & 2 & Reprodução da expressão toda & Sim & Sim \\
\hline 13 & & 2 & $\begin{array}{l}\text { Reprodução isolada de qualquer } \\
\text { pictograma da expressão }\end{array}$ & Sim & Não \\
\hline 14 & & 2 & $\begin{array}{l}\text { Compartilhamento da expressão } \\
\text { construída }\end{array}$ & Não & Não \\
\hline 15 & & 3 & Exclusão da expressão toda & Sim & Sim \\
\hline 16 & & 3 & $\begin{array}{l}\text { Exclusão de um pictograma da } \\
\text { expressão }\end{array}$ & Sim & Sim \\
\hline 17 & & 3 & $\begin{array}{l}\text { Alteração da posição de um } \\
\text { pictograma na expressão }\end{array}$ & Não & Não \\
\hline & & & $\begin{array}{l}\text { Sim } \\
\text { Não } \\
\end{array}$ & $\begin{array}{l}5(71,4 \%) \\
2(28,6 \%) \\
\end{array}$ & $\begin{array}{l}4(57,15 \%) \\
3(42,85 \%) \\
\end{array}$ \\
\hline 18 & \multirow{6}{*}{ Navegação } & 1 & Navegação sempre visível & Sim & Sim \\
\hline 19 & & 1 & Distinção entre categorias e elementos & Sim & Sim \\
\hline 20 & & 2 & Rolagem da tela por botão & Sim & Sim \\
\hline 21 & & 2 & Rolagem da tela por swipe & Sim & Sim \\
\hline 22 & & 3 & Navegação livre & Sim & Sim \\
\hline \multirow[t]{3}{*}{23} & & 6 & Uso intuitivo & Sim & Sim \\
\hline & & & $\begin{array}{l}\text { Sim } \\
\text { Não }\end{array}$ & $\begin{array}{c}6(100 \%) \\
0(0 \%)\end{array}$ & $\begin{array}{r}6(100 \%) \\
0(0 \%) \\
\end{array}$ \\
\hline & & & $\begin{array}{l}\text { Total Sim } \\
\text { Total Não }\end{array}$ & $\begin{array}{r}18(78,3 \%) \\
5(21,7 \%) \\
\end{array}$ & $\begin{array}{r}17(73,9 \%) \\
6(26,1 \%) \\
\end{array}$ \\
\hline
\end{tabular}

\section{Resultados Experimentais}

Para a validação dos recursos desenvolvidos neste PWA disponibilizado como um SaaS em https://panda.itp.ifsp.edu.br/, realizaram-se experimentos com usuários com limitações psicomotoras e diagnósticos com TEA, por meio de um modelo de estudo de caso exploratóriodescritivo, a partir da estrutura sequencial das ações de: planejamento, execução, avaliação e reflexão. De acordo com (Marconi \& Lakatos, 2004), esses procedimentos se justificam por não impactarem psicologicamente os alunos e por se tratar de uma avaliação descritiva, qualitativa e quantitativa pela perspectiva do observador. 
A quantidade de tempo em que os usuários utilizaram o App e a forma de uso (usabilidade) são considerados os itens avaliativos básicos nesta análise. Quanto a usabilidade, considerou-se o teste descrito em (Barbosa \& Silva, 2010) que tem como foco realizar avaliações quantitativas e qualitativas de acompanhamento no uso das ferramentas por meio de observações em atividades em que os usuários tem roteiro para sua execução e que deve atingir certos objetivos de uso (Figura 6) Essa prática foi adotada para se evitar o conceito de avaliação explícita dos usuários, devido ao perfil dos alunos que foram selecionados para o experimento.

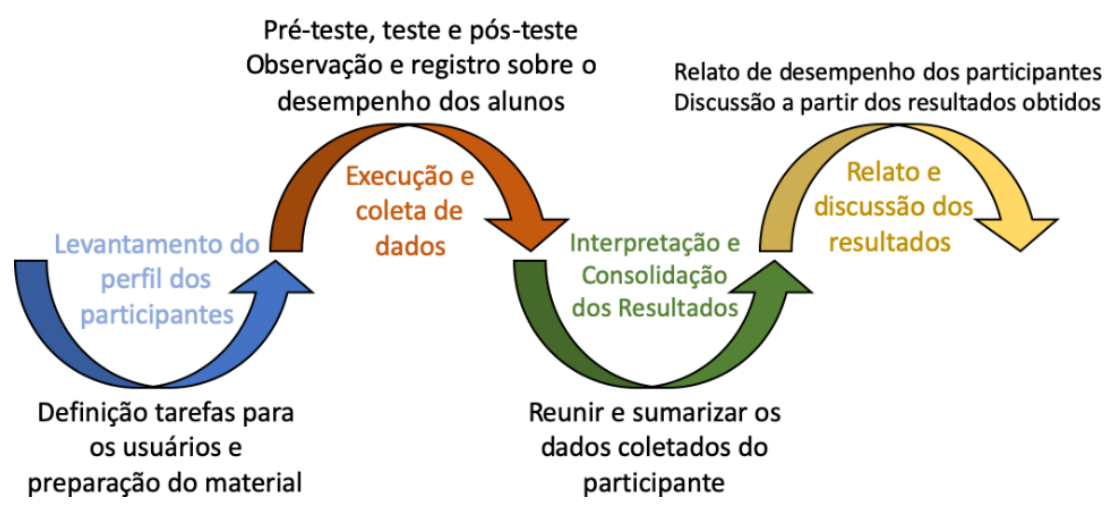

Figura 6: Esquemático do método de avaliação de usabilidade baseado em (Barbosa \& Silva, 2010).

Para isso, foi realizada uma parceria com a APAE (Associação de Pais e Amigos dos Excepcionais) na cidade de Itapetininga. Ela é uma instituição filantrópica fundada em 1971, cujo objetivo é prestar assistência às pessoas com deficiência intelectual, múltipla e autismo. No âmbito educacional, seu nome oficial é Escola de Educação Especial Dr. Armando de Paula Assis e atende hoje cerca de 210 alunos divididos entre o período da manhã e tarde. Na seção 6.1 é apresentada uma contextualização e perfil dos envolvidos no experimento para a coleta dos resultados, na seção 6.2 os resultados obtidos com os experimentos e, por fim, na seção 6.3 considerações acerca dos resultados.

\subsection{Contextualização e Descrição Populacional Envolvida nos Experimentos}

Nas dependências da APAE Itapetininga os alunos, além de trabalho educacional, também recebem suporte terapêutico por meio da equipe multidisciplinar constituída por psicólogos, fisioterapeutas, fonoaudióloga e assistência social, incluindo atendimentos de equoterapia e terapia multissensorial Snoezelen. Porém, não possuem recursos de informática ou jogos digitais para serem oferecidos aos alunos, devido à falta de recursos da instituição.

Os experimentos foram realizados em duas diferentes salas que são divididas por idades semelhantes, assim como graus de autismo. Onde possuíam alunos verbais e não verbais de 8 a 17 anos, com graus de autismo moderado a severo, sendo que apenas um era do sexo feminino. Partiu-se do requisito de que os investigados não tivessem utilizado o método PECS para que não se tivesse hábitos já adquiridos com outras ferramentas que pudessem influenciar nos resultados deste trabalho.

A primeira sala possuía 6 alunos com idades entre 12 e 17 anos, em que a liderança foi realizada por uma professora que trabalha há quatro anos com pessoas com deficiência intelectual e autistas. Tal sala foi caracterizada pela professora como tendo um bom comportamento, de forma que facilmente se realizariam as atividades propostas.

A segunda sala possuía 5 alunos com idades entre 8 e 11 anos, sendo que alguns apresentam comportamento agressivo e que não correspondiam de acordo com o esperado quando contrariados, dificultando o trabalho do professor na realização das atividades propostas. A professora responsável por essa turma trabalha há mais de dez anos com alunos que apresentam alguma deficiência. 
Como ponto de partida, foram realizados questionamentos às professoras para se compreender como elas conseguiam se comunicar com os alunos que não possuem habilidade verbal. As duas foram enfáticas ao afirmar que a comunicação ocorre com a convivência com eles, para compreender suas preferências e desejos, já que eles não faziam uso da ferramenta PECS. Nesse mesmo levantamento, verificou-se que havia apenas 3 alunos na instituição que tinham paralisia cerebral e utilizavam o método PECS, mas não foi possível caracterizar como eles construíram essa habilidade durante esta pesquisa. Porém, nenhum deles fazia parte do grupo pesquisado, por já terem contato com a técnica.

Antes de iniciar as avaliações com os alunos, realizou-se a observação das turmas para adequar o material com as imagens utilizadas nos livros e para conhecer e ser conhecido pelos alunos. Isso foi necessário principalmente pelo fato de que eles apresentam intolerância a mudanças em suas rotinas, ambientes e pessoas. Para esses experimentos foram disponibilizados pelo IFSP Campus Itapetininga 2 Tablets Samsung Galaxy Note 10.1 3G N8000, Galaxy Note 800, rodando Android 4.0.3 Ice Cream Sandwich ICS com processador 1.4Ghz Quad-Core ARM Cortex-A9, memória RAM 2GB LPDDR2 e 16GB de memória interna, e uma máquina fotográfica Nikon DSLR 5300 utilizada para filmar os experimentos para auxiliar na descrição dos relatos experimentais.

No pré-teste foi apresentado o aplicativo aos professores, mostrando as categorias existentes e como utilizar a ferramenta. Para os alunos, foi sugerido que explorassem a ferramenta para que as conhecessem quanto aos temas e as imagens inseridas. Essas categorias foram divididas em frutas, animais, brinquedos, roupas, vogais e numerais, conforme apresentado na Figura 7. Essa divisão foi realizada a partir de elementos simples contidos no cotidiano dos alunos.

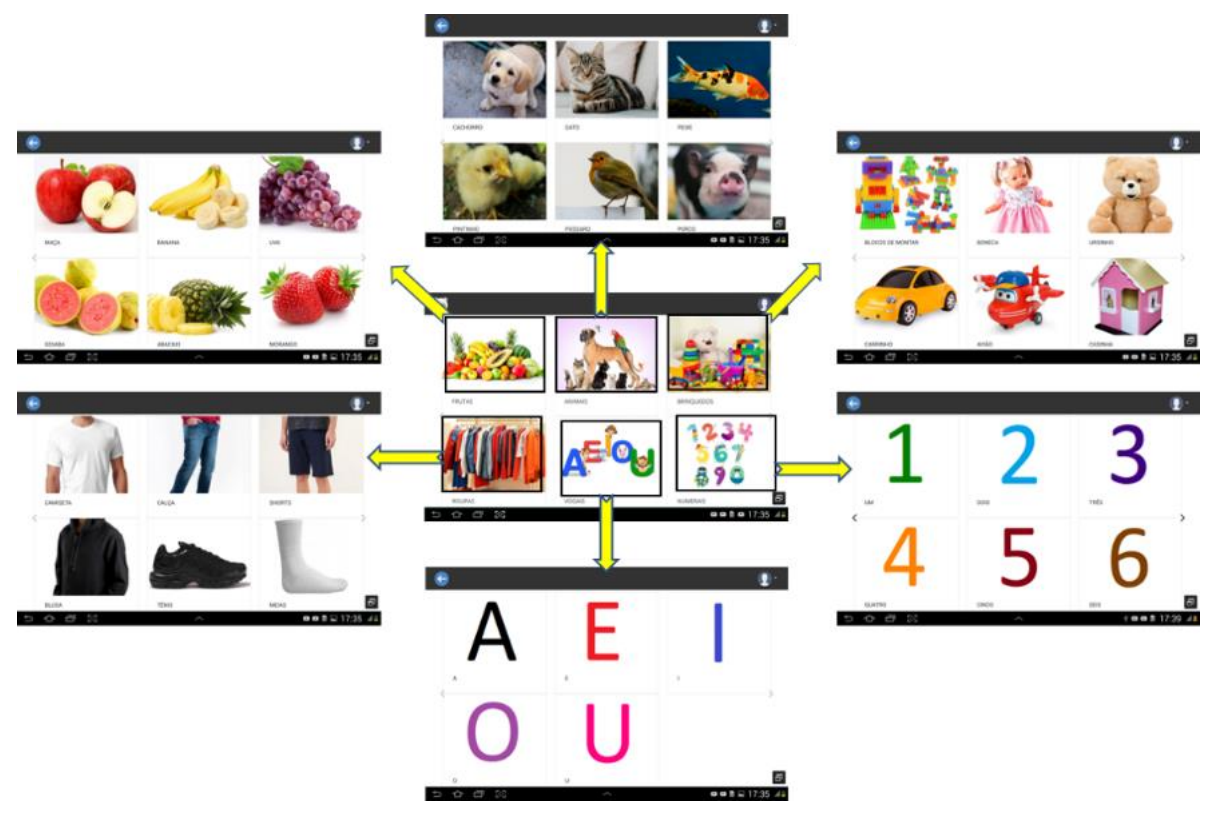

Figura 7: Hierarquia de escolha dos livros.

O teste considerou que o aluno já havia interagido com o aplicativo e foi iniciado convidando-os a selecionar uma categoria específica, partindo de solicitações como "onde estão as frutas?" e o aluno clicava em uma das figuras. Acessando a categoria, eles foram sucessivamente questionados quantas frutas eram exibidas. Esse procedimento foi realizado com algumas outras categorias. Nesta etapa não haviam consequências de acerto ou erro e nenhuma correção foi realizada, concluía-se essa fase após o aluno mostrar seis figuras sugeridas.

O pós-teste foi uma etapa também observacional em que os alunos pudessem continuar explorando livremente a ferramenta no tablet. Em todas essas etapas foram consideradas a avaliação e a reflexão, sendo: 
- Avaliação: foram levados em consideração os critérios de coordenação motora para utilização, atenção durante a tarefa, rápido desinteresse e acerto nas imagens sugeridas (acima de 50\%).

- Reflexão: as análises são apresentadas individualmente após a observação no local e revisão dos vídeos, indicando os resultados individualmente na Figura 8. A escolha por esse tipo de apresentação, partiu-se das especificidades dos alunos. Assim, logo após realizou-se uma discussão acerca dos resultados obtidos.

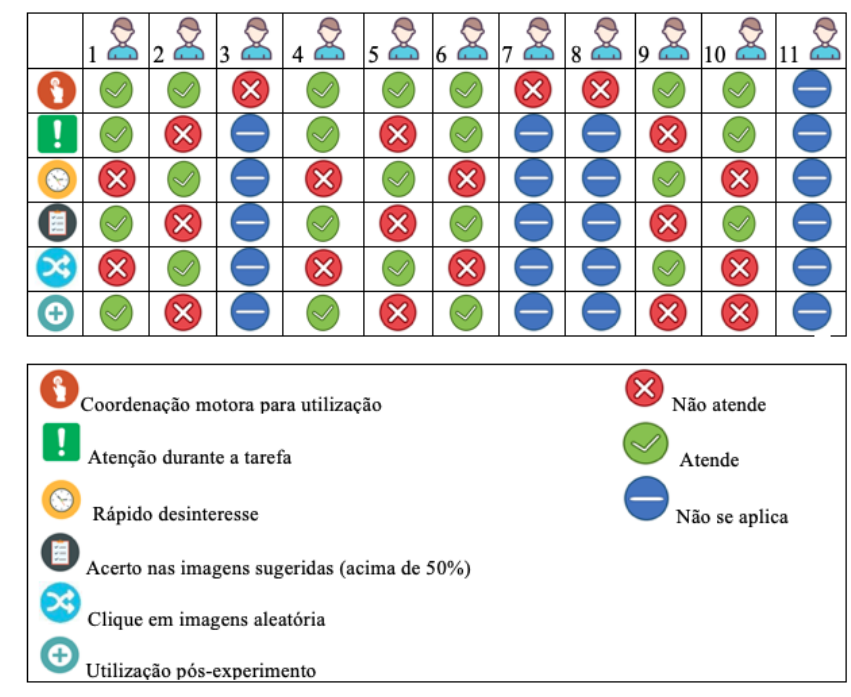

Figura 8: Funcionamento da escolha de livros.

\subsection{Resultados dos Experimentos Realizados}

Como indicado na Figura 8 por meio de uma matriz em que as colunas representam cada um dos 11 alunos das duas turmas, em que os experimentos foram realizados. $\mathrm{O} 11^{\circ}$ aluno não participou do experimento, ao ter se recusado de realizá-las. Porém, o símbolo azul com traço para "Não se Aplica" apresenta diferentes conceitos aos itens avaliados, devido aos déficits cognitivos e habilidades motoras serem bem variados, sendo que dois dos alunos que participaram tinha reduzida coordenação motora fina e um apresentava tremores nas mãos. A esses alunos foi disponibilizado auxílio para que pudessem selecionar as imagens, para que não gerasse a frustração por não conseguir participar do experimento.

Para facilitar a análise dos resultados apresentados na Figura 8, o gráfico em colunas apresentado na Figura 9 mostra a proporcionalidade dos resultados em relação aos valores absolutos para cada um dos seis critérios analisados, sendo:

- Coordenação Motora: verificação da capacidade motora dos alunos ao utilizarem a ferramenta. Como já mencionado, dos participantes do experimento, três não possuíam coordenação motora para realizar a tarefa, não conseguindo clicar nas imagens para o sintetizador de voz ler a descrição. Desses três, dois apresentavam tremores nas mãos e um possuía coordenação motora fina reduzida e quase nenhum movimento com as mãos, no entanto, se interessaram em utilizar a ferramenta, sendo auxiliados em todo o experimento para que não ficassem frustrados.

- Atenção durante as tarefas: avaliou-se o grau de atenção dos alunos na utilização da ferramenta, sendo que apenas $40 \%$ dos participantes avaliados tiveram atenção plena na realização das tarefas e três dos alunos se dispersavam facilmente, apesar de possuírem interesse na ferramenta e continuarem utilizando-a. Neste item o valor "Não se aplica" está relacionado aos alunos que precisavam de auxílio na utilização da 
ferramenta, logo não se pode distinguir se eles ficaram atentos somente por receberem auxílio ou se estivessem sozinhos manter-se-iam focados.

- Desinteresse dos alunos: este item considera o quão rápido os alunos se desinteressavam em utilizar a ferramenta ao longo dos experimentos, sendo que $30 \%$ deles demonstraram rápido desinteresse ao se dispersarem em fazer outra coisa, mas quando questionados seguiam com as atividades chegando até o final dos experimentos. Quatro alunos se mostraram bastante interessados durante todo o tempo e fixaram-se em explorar a ferramenta, mas vale destacar que possuíam grau moderado de autismo e déficit cognitivo menores que os outros.

- Acerto nas imagens sugeridas: os mesmos quatro alunos indicados no item anterior acertaram além de $50 \%$ do que foi proposto. Três alunos clicavam em imagens que não coincidiam com as que foram apresentadas ou, em alguns casos, selecionavam várias imagens quando sugerido uma imagem em específico. Novamente o valor de "Não se aplica", diz respeito aos alunos que necessitaram de algum tipo de ajuda para a realização das atividades.

- Clique em imagens aleatórias: neste tópico os alunos foram avaliados conforme o número de cliques em imagens aleatórias, ou seja, em figuras que não foram solicitadas pelo pesquisador. Dentro desse quadro apenas três alunos tinham esse comportamento e quatro deles seguiam o sugerido no experimento.

- Utilização no pós-teste: após as atividades guiadas sugeriu-se aos alunos que poderiam continuar utilizando a ferramenta quem quisesse, sendo que apenas três deles continuaram utilizando-a, interessados em exploras as demais categorias, quatro entregaram o tablet assim que completou as tarefas e três que seguiram apoiados pelos professores se enquadraram em "Não se aplica" não foram contabilizados por não responderem concretamente se continuariam a utilizar a ferramenta.

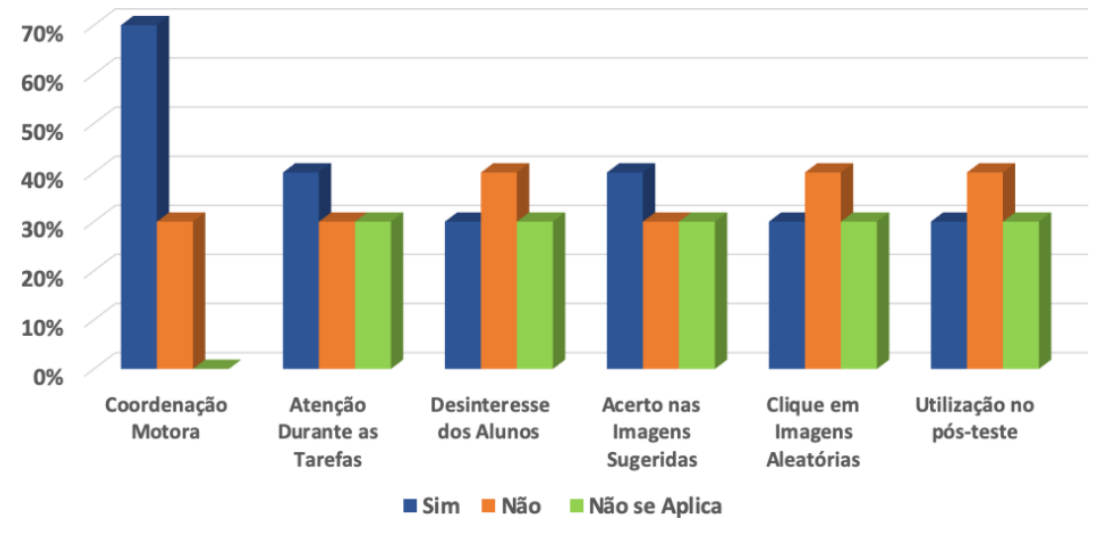

Figura 9: Resultados percentuais dos itens avaliados.

\subsection{Observações Acerca dos Resultados Obtidos}

Verificou-se ao longo do experimento que o recurso de swipe (arrasto direcionado para esquerda) para voltar a categoria anterior foi um dificultador, pois os alunos que apresentavam tremores nas mãos tinham dificuldade em pressionar o botão e isso as vezes faziam que ao invés de selecionar uma imagem eles voltassem uma categoria, o que os irritava por não conseguirem avançar com a tarefa solicitada.

Essa é uma observação interessante ao se considerar que é um requisito presente tanto no Panda quanto no aBoard de Franco et al. (2017), em que aqueles autores não apresentam resultados experimentais com o público-alvo. Além disso, neste trabalho em que é apresentado o 
Panda foram seguidas condições indicadas para testes e seu rigor necessário em análises de usabilidades de tecnologias assistivas para comunicação e ensino de pessoas com limitações psicomotoras, como as autistas, apresentadas por Tornblad, Jones e Inan (2019). Assim, tem-se como importante destaque a realização de observações prévias para a facilitação das práticas em sala de aula para conformação desse público, visando implicar menor impacto nos resultados apresentados quanto ao primeiro contato com pessoas novas para eles, portanto fora de seu ciclo habitual (Ferreira, et al., 2019).

\section{Conclusões}

Desenvolver uma Tecnologia Assistiva é uma atividade desafiadora, pois são necessários testes de software usuais na literatura e experimentos realizados com público-alvo de interesse, inclusive com pessoas que apresentam limitações mais severas tanto cognitivas quanto motoras (psicomotoras). Para isso, é necessário que haja uma equipe multidisciplinar com profissionais interconectados para se explorar os recursos disponibilizados pelas tecnologias e se conhecer os pontos que requerem melhorias. Portanto, mesmo com profissionais que tenham empatia com a situação dos usuários, não se consegue estabelecer um produto adequado ao uso das pessoas com limitações psicomotoras. Essa afirmação é justificada pelas comparações realizadas nas Tabelas 1 e 2, ao comparar com os resultados experimentais aqui apresentados, considerando o aBoard e a descrição feita pelos seus autores Franco et al. (2017).

O SaaS aqui apresentado é inovador por ser gratuito, possibilitar a criação de diferentes livros de comunicação e se tornar um aplicativo visual nativo para os diferentes dispositivos móveis, inclusive com recursos ultrapassados e limitados. Apresentados resultados experimentais satisfatórios com público-alvo que apresenta uma certa limitação motora e cognitiva, mas ainda limitado aos com limitações motoras mais severas.

Para isso, esse grupo agora trabalha em uma nova versão do software com reconhecimento de movimentos ortogonais da cabeça humana que em breve será testado com usuários. Isso também possibilitará integrar com plataformas de hardware abertas de baixo custo como, por exemplo, utilizando controladores Arduino (Nascimento Júnior et al., 2016), para controlar de cadeiras de rodas ou dispositivos conectados via software (IoT) com os movimentos da cabeça.

\section{Agradecimentos}

Os autores agradecem ao IFSP Campus Itapetininga e ao CNPq, pelo apoio parcial financeiro e de infraestrutura. Também agradecem à APAE Itapetininga pela disponibilidade e parceria para realizar as análises do Panda.

\section{Referências}

Alabbas, N. A., \& Miller, D. E. (2019). Challenges and assistive technology during typical routines: Perspectives of caregivers of children with autism spectrum disorders and other disabilities. doi: 10.1080/1034912X.2019.1578864 [GS Search]

Al-Batayneh, O., Nazer, T., Khader, Y., \& Owais, A. (2019). Effectiveness of a tooth-brushing programme using the picture exchange communication system (pecs) on gingival health of children with autism spectrum disorders. doi: 10.1007/s40368-019-00485-x [GS Search]

Aliverti, A. (2017). Wearable technology: role in respiratory health and disease. doi: $\underline{10.1183 / 20734735.008417 \text { [GS Search] }}$ 
Amos, B., Ludwiczuk, B., Satyanarayanan, M., et al. (2016). Openface: A general-purpose face recognition library with mobile applications. Disponível em: http://reportsarchive.adm.cs.cmu.edu/anon/anon/usr0/ftp/2016/CMU-CS-16-118.pdf Acesso em: 12/11/2020 [GS Search]

Barbosa, S., \& Silva, B. (2010). Interação humano-computador. Elsevier, ISBN 978-85-3523418-3 [GS Search]

Basques, K. (2020). View application cache data with chrome devtools. Disponível em: https://developers.google.com/web/tools/chrome-devtools/storage/cache, Acesso em 13/06/2020.

Benesová, A., \& Tupa, J. (2017). Requirements for education and qualification of people in industry 4.0. Disponível em: https://doi.org/10.1016/j.promfg.2017.07.366 Acesso em: 12/11/2020 [GS Search]

Bhushan, S. B., Reddy, P., Subramanian, D. V., \& Gao, X. (2018). Systematic survey on evolutionof cloud architectures. doi: 10.1504/IJAACS.2018.090661 [GS Search]

Biørn-Hansen, A., Majchrzak, T. A., \& Grønli, T.-M. (2017). Progressive web apps: The possible web-native unifier for mobile development. doi: 10.5220/0006353703440351 [GS Search]

Briand, L., Nejati, S., Sabetzadeh, M., \& Bianculli, D. (2016). Testing the untestable: model testing of complex software-intensive systems. doi: 10.1145/2889160.2889212 [GS Search]

Bruno, R., Schuchman, L., Cunningham, K., \& McCarthy, R. (2001, May 1). System for providing a simultaneous data and voice channel within a single channel of a portable cellular telephone to provide position-enhanced cellular services (pecs). Google Patents. Disponível em: https://patents.google.com/patent/US6226529B1/en Acesso em: 12/11/2020 [GS Search]

Bueno, D. C. (2017). Hymob web: Uma abordagem para a adaptação híbrida de interfaces web móveis sensíveis ao contexto e com suporte à multimodalidade. Disponível em: https://repositorio.ufscar.br/handle/ufscar/9157 Acesso em: 12/11/2020 [GS Search]

Cândido, P. H. V. (2017). Problemas de interação na adaptação de interface web móvel em frameworks front-end. doi: 10.13140/RG.2.2.12982.73284 [GS Search]

Cesário, V., Rodrigues, J., Li, H., Wu, I., \& Nisi, V. (2016). Crescendo: Routine Learning App for Children with Autism Spectrum Disorders. doi: 10.1145/2930674.2935997 [GS Search]

Chatterjee, A., Aceves, A., Dungca, R., Flores, H., \& Giddens, K. (2016). Classification of wearable computing: A survey of electronic assistive technology and future design. doi: $\underline{10.1109 / \text { ICRCICN.2016.7813545 [GS Search] }}$

Cramer, M., Hirano, S. H., Tentori, M., Yeganyan, M. T., \& Hayes, G. R. (2011). Classroombased assistive technology: collective use of interactive visual schedules by students with autism. 10.1145/1978942.1978944 [GS Search]

da Silva, A. C., Correa, L. R., Dias, L. A. V., \& da Cunha, A. M. (2015). A case study using testing technique for software as a service (SaaS). doi: 10.1109/ITNG.2015.133 [GS Search]

da Silva, A. D. M., \& do Nascimento, K. L. (2019). Desafios socioeducacionais na sociedade em rede: sobre inclusão digital e usos educacionais de computadores em escolas públicas de Natal-RN. doi: 10.21680/1981-1802.2019v57n52ID16445 [GS Search]

Da Silva Júnior, E. F., Da Hora Rodrigues \& K. R. (2019) Ferramentas Computacionais como Soluções Viáveis para Alfabetização e Comunicação Alternativa de Crianças Autistas: Um Mapeamento Sistemático sobre as Tecnologias Assistivas Existentes. doi: 10.5753/waihcws.2019.7678 [GS Search] 
Dias, A. C. V. M. (2016). Diagnostic practices of autism spectrum disorders in brazil. [GS Search]

Doosti, B., Dong, T., Deka, B., \& Nichols, J. (2018). A computational method for evaluating UI Patterns. Disponível em: https://arxiv.org/abs/1807.04191. Acesso em: 12/11/2020. [GS Search]

Esposito, A., Esposito, A. M., \& Vogel, C. (2015). Needs and challenges in human computer interaction for processing social emotional information. doi: 10.1016/j.patrec.2015.02.013 [GS Search]

Farias, E. B., Silva, L. W., \& Cunha, M. X. (2014). ABC AUTISMO: Um aplicativo móvel para auxiliar na alfabetização de crianças com autismo baseado no Programa TEACCH. https://doi.org/10.5753/sbsi.2014.6136 [GS Search]

Ferreira, A. C. D., Barros, J. D. F., Coquerel, P. R. S., Morais, M. P. S. D., Benjamim, E. E. R. B., Andrade, E. H. S., ... \& Silva, A. R. D. (2019). Efeitos de sessões de psicomotricidade relacional sobre o perfil das habilidades motoras e controle postural em indivíduo com transtorno do espectro autista. Disponível em: https://repositorio.unb.br/bitstream/10482/39441/1/LIVRO_EfeitosSessoesPsicomotricidad e.pdf. Acesso em: 12/11/2020.

Franco, N., Lima, T., Lima, A., Silva, E., Lima, R., Cavalcante, T., \& Fidalgo, R. (2017). aBoard: Uma Plataforma para Educação Inclusiva a partir de Comunicação Aumentativa e/ou Alternativa. doi: 10.5753/cbie.sbie.2017.977. Acesso em: 12/11/2020. [GS Search]

Freitas, M. A. G. d. (2018). Microservices applied to web and mobile applications internship. doi: $\underline{10400.1 / 12368}$ [GS Search]

Gaunt, M. (2019). Service workers: an introduction. Disponível em: https://developers.google.com/web/fundamentals/primers/service-workers Acesso em: 12/11/2020 [GS Search]

Girdhar, A., Srivastava, G., \& Rawat, S. (2019). System and method for creating, distributing \& rendering progressive web applications. Google Patents. Disponível em: https://patents.google.com/patent/US20190065217A1/en Acesso em: 12/11/2020. [GS $\underline{\text { Search }}$

Grigera, J., Garrido, A., Rivero, J. M., \& Rossi, G. (2017). Automatic detection of usability smellsin web applications. doi: 10.1016/j.ijhcs.2016.09.009 [GS Search]

Hamdan, O., Shanableh, H., Zaki, I., Al-Ali, A., \& Shanableh, T. (2019). Iot-based interactive dual mode smart home automation. doi: 10.1109/ICCE.2019.8661935 [GS Search]

Harari, Y. N. (2016). Homo deus: uma breve história do amanhã. Companhia das Letras. [GS Search]

Harb, E., Kapellari, P., Luong, S., \& Spot, N. (2011). Responsive web design. Dec Disponível em: https://courses.isds.tugraz.at/iaweb/surveys/ws2011/g3-survey-resp-webdesign.pdf Acesso em: 12/11/2020. [GS Search]

Jain, N. (2015). Review of different responsive CSS front-end frameworks. [GS Search]

Johnston, S. K., \& Palaniappan, R. (2015, May 5). Distributed workflow management system. Google Patents. Disponível em: https://patentimages.storage.googleapis.com/7f/9c/db/ca2502bbaf74a1/US9026577.pdf Acesso em: 12/11/2020. [GS Search]

Landgren, E. (2019). tracking.js. Disponível em: https://trackingjs.com/. Acesso em 11 de Junho de 2020 . 
Logan, S. W., Ross, S. M., Chee, K., Stodden, D. F., \& Robinson, L. E. (2018). Fundamental motor skills: A systematic review of terminology. doi: 10.1080/02640414.2017.1340660 [GS $\underline{\text { Search }}$

Ma, M., Yang, J., Wang, P., Liu, W., \& Zhang, J. (2019). Light-weight and scalable hierarchicalmvc architecture for cloud web applications. doi: 10.1109/CSCloud/EdgeCom.2019.00017 [GS Search]

Maïano, C., Hue, O., \& April, J. (2019). Fundamental movement skills in children and adolescents with intellectual disabilities: a systematic review. doi: 10.1111/jar.12606 [GS Search]

Maldonado, J. C., Braga, R. T. V., Germano, F. S. R., \& Masiero, P. C. (2002). Padrões e frameworks de software. Disponível em: https://sites.icmc.usp.br/rtvb/apostila.pdf Acesso em: 12/11/2020 [GS Search]

Mania, F., da Silva Santos, C. H., \& Alvaro, A. (2014). Outlining low costs and open embedded systems for rfid in internet of things applications. 10.1109/BrasilRFID.2014.7128954 [GS $\underline{\text { Search }] ~}$

Marconi, M. d. A., \& Lakatos, E. M. (2004). Metodologia científica (Vol. 4). [GS Search]

Mentone, E. C. P., \& Fortunato, I. (2019). A tecnologia digital no auxílio à educação de autistas: os aplicativos ABC autismo, aiello e Scai autismo. Temas em Educação e Saúde. doi: $\underline{10.26673 / \text { tes.v15i1.12733 [GS Search] }}$

Network, Mozilla Developer. (2018). Using the application cache. Disponível em: https://developer.mozilla.org/pt-BR/docs/Web/HTML/Using the application_cache Acesso em: 12/11/2020. [GS Search]

Mendonça N. C., Jamshidi, P., Garlan, D., \& Pahl, C. (2019). Developing self-adaptive microservice systems: Challenges and directions. doi: $\underline{10.1109 / \mathrm{MS} .2019 .2955937}$ [GS Search]

Mortazavi, S. H., Salehe, M., Gomes, C. S., Phillips, C., \& de Lara, E. (2017). Cloudpath: a multi-tier cloud computing framework. doi: 10.1145/3132211.3134464 [GS Search]

Mukhopadhyay, D. (2019, November 28). Assistive device for the visually-impaired. Disponível em: https://patentscope.wipo.int/search/en/detail.jsf?docId=WO2019231643.

Munteanu, C., Molyneaux, H., Moncur, W., Romero, M., O’Donnell, S., \& Vines, J. (2015). Situational ethics: Re-thinking approaches to formal ethics requirements for humancomputer interaction. doi: 10.1145/2702123.2702481 [GS Search]

Nascimento Júnior, A., et al. (2016). Robotização de uma cadeira de rodas motorizada: arquitetura, modelos, controle e aplicações. Disponível em: http://repositorio.unicamp.br/handle/REPOSIP/321685. Acesso em 11 de Junho de 2020. [GS Search]

Paim, L. E. P. (2019). A tecnologia educacional e o transtorno do espectro autista (TEA): possibilidades e desafios na alfabetização. Disponível em: https://www.lume.ufrgs.br/bitstream/handle/10183/197648/001098667.pdf?sequence=1 Acesso em 12 de Novembro de 2020. [GS Search].

Pop, D. (2016). Machine learning and cloud computing: Survey of distributed and saas solutions. Disponível em: https://arxiv.org/abs/1603.08767. Acesso em 11 de Junho de 2020. [GS $\underline{\text { Search }}$

Portolese, J., Bordini, D., Lowenthal, R., Zachi, E. C., \& Paula, C. S. d. (2017). Mapeamento dosservic os que prestam atendimento a pessoas com transtorno do espectro autista no brasil. 
Disponível em: http://editorarevistas.mackenzie.br/index.php/cpgdd/article/view/11322. Acesso em 11 de Junho de 2020. [GS Search]

Pugh, W., Eakes, M., Bernander, O., \& Gundavaram, P. (2015, March 24). Unified workspace forthin, remote, and saas applications. Google Patents. Disponível em: https://patents.google.com/patent/US8990699B2/en. Acesso em 11 de Junho de 2020. [GS Search]

Raja, P., Saringat, M. Z., Mustapha, A., \& Zainal, A. (2017). Prospect: A picture exchangecommunication system (pecs)-based instant messaging application for autism spectrumcondition. doi: 10.1088/1757-899X/226/1/012088 [GS Search]

Ramaci, J. E. (2019, March 28). Method and system for assistive electronic detailing ecosystem.Google Patents. Disponível em: https://patents.google.com/patent/US20190096533A1/en. Acesso em 11 de Junho de 2020. [GS Search]

Rangasamy, V., Kumar, P., Jeyapaul, J., \& Lillie, B. J. (2016, May 5). Microservicebasedapplication development framework. US10230571B2 [US Patents].

Salihbasíc, A., \& Orehovacki, T. (2019). Development of android application for gender, age andface recognition using opencv. doi: 10.23919/MIPRO.2019.8756700 [GS Search]

Sayem, I. M., \& Chowdhury, M. S. (2018). Integrating face recognition security system with theinternet of things. doi: 10.1109/iCMLDE.2018.00013 [GS Search]

SEKSENOV, K. N., Chinnathambi, K., HILL, K. J., \& BURTOFT, J. C. (2019, May 30).Progressive web app auto-ingestion. Google Patents. Disponível em: https://patents.google.com/patent/US10496381B2/en. Acesso em 11 de Junho de 2020 [GS $\underline{\text { Search }] ~}$

Siddiqui, T., \& Ahmad, R.(2016). A review on software testing approaches for cloud applications. doi: $10.1016 /$ j.pisc.2016.06.060. [GS Search]

Soderstrom, U., Carlsson, L., \& Mejtoft, T. (2019). Comparing millennials view on minimalismand maximalism in web design. doi: 10.1145/3335082.3335104 [GS Search]

Stauffer, M. (2019). Laravel: Up \& running: A framework for building modern php apps. O'Reilly [GS Search]

Suh, Y. T., \& Kim, Y. J. (2016). Effect of psychomotricity program on anxiety, withdrawal and problem behavior of children with asperger disorder. doi: $10.17485 / \mathrm{ijst} / 2016 / \mathrm{v} 9 \mathrm{i} 25 / 97150$ [GS Search]

Tang, N., Hu, H., Xu, F., \& Zhu, F. (2019). Personalized safety instruction system for construction site based on internet technology. doi: 10.1016/j.ssci.2019.03.001 [GS Search]

Tornblad, M. K., Jones, K. S., \& Inan, F. A. (2019). Individuals with autism spectrum disorder: A review of human factors considerations and usability testing guidelines. doi: $\underline{10.1177 / 1071181319631423}$ [GS Search]

Toxboe, A. (2016). Ui-patterns. Disponível em: https://ui-patterns.com/. Acesso em 11 de Junho de 2020 [GS Search]

Tsai, W.-T., \& Qi, G. (2017). Adaptive reasoning algorithm with automated test cases generation and test algebra in SaaS System. In Combinatorial testing in cloud computing (pp. 83-99). doi: 10.1007/978-981-10-4481-6 7. [GS Search]

Upadhyay, J., Rida, P., Gupta, S., \& Siddique, N. (2017). Smart doorbell system based on face recognition. [GS Search] 
Wang, R. (2020). Design of mini pets feeding intelligent home system based on IoT. In Advances in intelligent information hiding and multimedia signal processing (pp. 31-40). doi: $\underline{10.1007 / 978-981-13-9714-1 \_4 \text { [GS Search] }}$ 